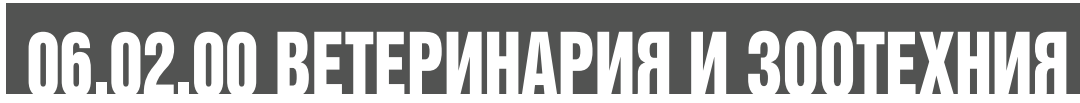

\section{ОЦЕНКА МОРФОФУНКЦИОНАЛЬНЫХ СВОЙСТВ ВЫМЕНИ КОРОВ СИММЕНТАЛЬСКОЙ ПОРОДЫ РАЗНЫХ ВНУТРИПОРОДНЫХ ТИПОВ}

\author{
Анисимова Екатерина Ивановна ${ }^{1}$, доктор сельскохозяйственных наук \\ Катмаков Петр Сергеевич ${ }^{2}$, доктор сельскохозяйственных наук, профессор кафедры \\ "Кормление и разведение животных» \\ ${ }^{1}$ ФГБНУ «Научно-исследовательский институт Юго-Востока» \\ 2ФГБОУ ВО УЛЬянОвскИй ГАУ \\ 432017, г. Ульяновск, бульвар Новый Венеи, 1; тел.: 8(8422)44-30-62; \\ e-mail: ulbiotech@yandex.ru
}

Ключевые слова: симментальская порода, внутрипородный тип, конституция, морфологическая оценка, функциональные свойства, корреляция, наследуемость, индексвымени, интенсивностьмолокоотдачи, пластичность породы.

Работа посвящена оценке морфофункциональных свойств вымени коров симментальской породы разных внутрипородных типов. Установлено, что среди животных молочного типа желательную чашеобразную форму вымени имели 70,3 \% коров. Этот показатель на 4,3-21,5 \% больше, чем у представительниц молочно-мясного и мясо-молочного типов. Коровы с чашеобразной формой вымени показали продуктивность по третьей лактации 5500-5700 кг молока и превосходили сверстниц, имеющих округлую фрорму вымени, на 900 кг и с козьим выменем - на 1300 кг. Коровы молочного типа характеризуются более объемным выменем, общая балльная оценка которых составляет 4,5 балла, у коров молочно-мясного типа - 4,2 и мясо-молочного типа - 4.0 балла. Выявлена положительная корреляция между удоем коров и объемом их вымени. У коров молочного типа она составила 0,376, а у коров молочно-мясного и мясо-молочного типов соответственно 0,347 и 0,264. Установлено, что у коров молочного типа промеры обхвата, длины и ширины вымени были больше, чем у коров других внутрипородных типов, соответственно на 3,7-4,9; 1,3-2,1 и 1,1-1,8 см. Наиболее высокой интенсивностью молокоотдачи характеризовались также коровы молочного типа, у которых данный показатель был выше, в сравнении со сверстницами молочно-мясного и мясо-молочного типов, по первой лактации на 0,11-0,32 кг/мин., второй - на 0,11-0,18 кг/мин. и по третьей - на 0,29-0,42 кг/мин. Коровы молочного типа более технологичны, индекс вымени у них составил 44,7 \%, близкие показатели имели коровы молочно-мясного типа с индексом 43,2 \%, и менее технологичными являются коровы мясо-молочного типа с индексом вымени 40,6 \%. Из общего суточного удоя коров молочного типа на долю передних четвертей вымени приходится 44,7\%, задних - 55,3 \%, правой половины - 51,8 \%, левой половины - $48,2 \%$.

\section{Введение}

Симментальская порода, как порода комбинированного направления продуктивности и наиболее пластичная среди других пород, значительно варьирует в производственных типах от молочного до мясо-молочного. Универсальность в отношении продуктивности, качественный состав молока, пригодного не только для производства кисломолочных продуктов, но и твердых сыров, высокая мясная продуктивность, за счет которой в регионе в основном решается проблема производства говядины, крепость конституции и способность приспособительно реагировать и изменяться при смене среды обитания, что крайне важно в экстремальных климатических условиях, - все это выдвигает симмен- 
Распределение коров по форме вымени

\begin{tabular}{|c|c|c|c|c|}
\hline \multirow{2}{*}{ Внутрипородный тип } & \multirow{2}{*}{ Число коров } & \multicolumn{3}{|c|}{ Форма вымени, \% } \\
\hline & & чашеобразная & округлая & козья \\
\hline Молочный & 40 & 70,3 & 29,7 & - \\
\hline Молочно-мясной & 57 & 66,0 & 31,5 & 2,5 \\
\hline Мясо-молочный & 25 & 48,8 & 46,6 & 4,6 \\
\hline В среднем & 122 & 57,7 & 38,8 & 3,5 \\
\hline
\end{tabular}

талов в число ведущих пород крупного рогатого скота, длительно разводимых в большинстве районов и хозяйств всех форм собственности в Поволжье.

В условиях промышленной технологии производства молока важным селекционным признаком является пригодность коров к машинному доению. В связи с этим большое значение имеет оценка морфофизиологических свойств вымени коров симментальской породы: формы, размеров, расположения вымени, равномерности развития долей, размеров и формы сосков, интенсивность молокоотдачи, так как большая часть этих признаков коррелирует с уровнем молочной продуктивности [1], а интенсивность молокоотдачи и продолжительность выдаивания позволяют судить о реакции коровы на доильный процесс [2].

Наличие положительной связи между формой вымени и удоем отмечают в своих работах многие авторы [3-10], хотя, по мнению И.Г. Велиток [11], форма вымени, как визуально-субъективный показатель, вряд ли играет существенную роль в определении пригодности коров к машинному доению. Примерно таких взглядов придерживаются и И. Иоганнсон, Я Рендель, О. Граверт [12]. По их данным, вследствие субъективной оценки, не лишенной погрешностей, наследуемость формы вымени у 30 тыс. коров оказалась низкой, в пределах 0,08-0,21.

По Ф.Л. Гарькавому [13], промеры вымени и сосков представляют объективную характеристику их развития и формы, находятся в связи с продуктивностью и пригодностью к машинному доению. Им получены близкие по своему значению корреляции отдельных промеров и вычисленного по ним объема вымени с удоем коров $(r=0,56-0,74)$. По данным А.С Всяких [14], коэффициент корреляции между удоем и размерами вымени составляет 0,37-0,66.

\section{Объекты и методы исследований}

Исследования проведены в стаде симментальской породы скота племенного репродуктора «Красавский» Саратовской области. Объектами исследований были чистопородные животные симментальской породы. Пригодность коров к машинному доению оценивали визуально по форме вымени и путем взятия промеров. Морфологическую оценку проводили на 2-3 месяцах лактации за 0,5-1,0 часа до доения, пользуясь следующей классификацией: чашеобразное, округлое, козье. Интенсивность молокоотдачи оценивали при контрольном доении коров по средним данным за две смежные дойки. При этом определяли продолжительность доения, суточный удой, а также удой в четвертях вымени, пользуясь аппаратом для раздельного выдаивания четвертей вымени ДАЧ-1.

Статистическую обработку материалов исследований проводили по методике Е.К. Меркурьевой [15], на персональном компьютере с использованием программ Microsoft Excel.

\section{Результаты исследований}

При оценке коров разных внутрипородных типов по форме вымени выявлено, что среди коров молочного типа желательную чашеобразную форму вымени имели 70,3 \% коров. Этот показатель на 4,3-21,5 \% больше, чем у представительниц молочно-мясного и мясо-молочного типов (табл. 1).

Данные, полученные в процессе исследований, подтверждают, что между объемом вымени и среднесуточным удоем симментальских коров связь положительная и составляет $r$ $=0,368$, а удоем за лактацию $r=0,329$. Коровы с чашеобразной формой вымени показывают продуктивность по третьей лактации 5500-5700 кг молока и превосходят сверстниц, имеющих округлую форму вымени, на 900 кг и с козьим выменем - на 1300 кг. Коровы молочного типа характеризуются более объемным выменем, общая балльная оценка которых составляет 4,5 балла, в то время как у коров молочно-мясного типа -4,2 и мясо-молочного - 4,0 балла.

У коров молочного типа промеры обхвата, длины и ширины вымени были больше, чем у коров других внутрипородных типов, соответственно на 3,7-4,9; 1,3-2,1 и 1,1-1,8 см. Их превосходство по глубине передних четвертей вымени составило 0,3-1,2 см, расстоянию между передними, задними и боковыми сосками - 0,7-1,4; 1,3-2,6 и 0,5-1,4 см (табл. 2). 
Таблица 2

Промеры вымени и сосков симментальских коров разных внутрипородных типов, см

\begin{tabular}{|l|c|c|c|}
\hline \multirow{2}{*}{ Показатель } & \multicolumn{3}{|c|}{ Внутрипородный тип } \\
\cline { 2 - 4 } & молочный & $\begin{array}{c}\text { молочно- } \\
\text { мясной }\end{array}$ & $\begin{array}{c}\text { мясо- } \\
\text { молочный }\end{array}$ \\
\hline Голов & 10 & 10 & 10 \\
\hline Обхват вымени & $108,2 \pm 0,86$ & $104,5 \pm 0,94$ & $103,3 \pm 1,03$ \\
\hline Длина вымени & $32,7 \pm 0,63$ & $31,4 \pm 0,76$ & $30,6 \pm 0,91$ \\
\hline Ширина вымени & $25,6 \pm 0,58$ & $24,5 \pm 0,53$ & $23,8 \pm 0,72$ \\
\hline Глубина вымени & $23,7 \pm 0,41$ & $23,4 \pm 0,30$ & $22,5 \pm 0,50$ \\
\hline Высота над землей & $60,4 \pm 0,63$ & $57,5+0,76$ & $57,0 \pm 0,59$ \\
\hline Длина передних сосков & $6,4 \pm 0,16$ & $6,4 \pm 0,18$ & $6,5 \pm 0,22$ \\
\hline Диаметр передних сосков & $2,5 \pm 0,06$ & $2,4 \pm 0,08$ & $2,3 \pm 0,05$ \\
\hline $\begin{array}{l}\text { Расстояние между: } \\
\text { передними сосками }\end{array}$ & $14,2 \pm 0,31$ & $13,5 \pm 0,53$ & $12,8 \pm 0,42$ \\
\hline задними & $9,8 \pm 0,29$ & $8,5 \pm 0,35$ & $7,2 \pm 0,34$ \\
\hline боковыми & $9,2 \pm 0,14$ & $8,7 \pm 0,22$ & $7,8 \pm 0,13$ \\
\hline
\end{tabular}

Одним из важнейших селекционных признаков, определяющих пригодность коров к машинному доению, является интенсивность молокоотдачи. Коровы с быстрой и легкой молокоотдачей более пригодны к машинному доению и экономически выгодны для хозяйства. Интенсивность молокоотдачи находится в прямой зависимости от уровня продуктивности (величины суточного удоя и удоя за лактацию), принадлежности коров к разным внутрипородным типам, анатомо-физиологических свойств вымени, породы и других факторов. Хорошая форма вымени улучшает отдачу молока и ограничивает опасность инфекции, а также обусловливает более равномерное распределение молока по всем долям вымени.

При изучении функциональных свойств вымени коров нами выявлены значительные межтиповые различия по реакции на доильный процесс.

Наиболее высокой интенсивностью моло- коотдачи характеризовались коровы молочного типа, у которых данный показатель был выше, в сравнении со сверстницами молочно-мясного и мясо-молочного типов: по первой лактации - на 0,11-0,32 кг/мин., второй - на 0,11-0,18 кг/мин. и по третьей - на 0,29-0,42 кг/мин. (табл. 3).

Объективным показателем развития и функционального состояния вымени является соотношение удоя из отдельных четвертей вымени. Вымя коровы должно быть равномерно развито, с тем чтобы удой из двух передних четвертей составил не менее 40 \% общего удоя. В противном случае в конце механического доения передние соски будут доиться "вхолостую», что может привести к их травматическим повреждениям или заболеванию маститом. В наших исследованиях среднесуточный удой симментальских коров молочного типа в среднем был выше, чем у сверстниц молочно-мясного и мясомолочного типов, на 2,1-7,2 кг, а интенсивность молокоотдачи - на 0,12-0,27 кг/мин. (табл. 4).

Более технологичными оказались коровы молочного типа, у которых индекс вымени составляет 44,7 \%, близкие показатели имели коровы молочно-мясного типа с индексом 43,2 \%, и менее технологичными являются коровы мясо-молочного типа, характеризующиеся самыми низкими показателями суточного удоя, интенсивности молокоотдачи и индекса вымени (40,6 $\%)$.

Полученные данные показывают на более равномерное распределение удоя по четвертям вымени у коров молочного типа. Из общего суточного удоя коров на долю передних четвертей вымени приходится 44,7 \%, задних - 55,3 \%, правой половины - 51,8 \% и левой половины - 48,2

Таблица 3

Удой за лактацию и интенсивность молокоотдачи у коров разных внутрипородных типов

\begin{tabular}{|c|c|c|c|}
\hline \multirow{2}{*}{ Показатель } & \multicolumn{3}{|c|}{ Лактация } \\
\hline & 1 & 2 & 3 \\
\hline \multicolumn{4}{|c|}{ Молочный (п = 10) } \\
\hline Удой, кг & $4362 \pm 157$ & $5131 \pm 165$ & $5847 \pm 152$ \\
\hline Интенсивность молокоотдачи, кг/мин. & $1,28 \pm 0,01$ & $1,30 \pm 0,03$ & $1.59 \pm 0,02$ \\
\hline \multicolumn{4}{|c|}{ Молочно-мясной (п=10) } \\
\hline Удой, кг & $3343 \pm 259$ & $4168 \pm 149$ & $4759 \pm 157$ \\
\hline Интенсивность молокоотдачи, кг/мин. & $1,17 \pm 0,02$ & $1,19 \pm 0.02$ & $1,30 \pm 0,03$ \\
\hline \multicolumn{4}{|c|}{ Мясо-молочный ( п=10) } \\
\hline Удой, кг & $2584 \pm 260$ & $2704 \pm 241$ & $3321 \pm 178$ \\
\hline Интенсивность молокоотдачи, кг/мин. & $0.96 \pm 0,01$ & $1,12 \pm 0,01$ & $1,17 \pm 0,02$ \\
\hline
\end{tabular}


Таблица 4

Функциональные свойства вымени коров

\begin{tabular}{|l|c|c|c|}
\hline \multirow{2}{*}{ Признак } & \multicolumn{3}{|c|}{ Внутрипородный тип } \\
\cline { 2 - 4 } & молочный & молочно-мясной & мясо-молочный \\
\hline Суточный удой, кг & $18,0 \pm 0,57$ & $15,9 \pm 0,55$ & $10,8 \pm 0,56$ \\
\hline Интенсивность молокоотдачи, кг/мин. & $1,35 \pm 0,01$ & $1,23 \pm 0,02$ & $1,08 \pm 0,02$ \\
\hline Индекс вымени, \% & 44,7 & 43,2 & 40,6 \\
\hline
\end{tabular}

Соотношение удоев четвертей и индекс вымени, \%

\begin{tabular}{|c|c|c|c|c|c|c|c|c|}
\hline \multirow{3}{*}{$\begin{array}{l}\text { Время } \\
\text { суток }\end{array}$} & \multicolumn{6}{|c|}{ Доля вымени } & \multicolumn{2}{|c|}{ Половина вымени } \\
\hline & \multicolumn{2}{|c|}{ правая } & \multirow{2}{*}{\begin{tabular}{|c|} 
левая \\
передн. \\
\end{tabular}} & \multicolumn{2}{|c|}{ передн. } & \multirow{2}{*}{$\begin{array}{l}\text { задняя } \\
\text { доля }\end{array}$} & \multirow{2}{*}{ правая } & \multirow{2}{*}{ левая } \\
\hline & передн. & задняя & & задняя & доля & & & \\
\hline \multicolumn{9}{|c|}{ Молочный тип (п=10) } \\
\hline Утро & 23,5 & 28,6 & 22,4 & 25,5 & 45,9 & 54,1 & 52,1 & 47,9 \\
\hline Обед & 22,7 & 28,6 & 21,4 & 27,3 & 44,1 & 55,9 & 51,3 & 48,7 \\
\hline Вечер & 23,2 & 29,0 & 21,1 & 26,7 & 44,3 & 55,7 & 52,2 & 47,8 \\
\hline За сутки & 23,1 & 28,7 & 21,6 & 26,6 & 44,7 & 55,3 & 51,8 & 48,2 \\
\hline \multicolumn{9}{|c|}{ Молочно-мясной тип (п=10) } \\
\hline Утро & 22,0 & 29,2 & 20,0 & 28,8 & 42,0 & 58,0 & 51,2 & 48,8 \\
\hline Обед & 20,8 & 28,4 & 21,8 & 29,0 & 42,6 & 57,4 & 49,2 & 50,8 \\
\hline Вечер & 22,6 & 27,5 & 22,6 & 27,3 & 45,2 & 54,8 & 50,1 & 49,9 \\
\hline За сутки & 21,8 & 28,5 & 21,4 & 28,3 & 43,2 & 56,8 & 50,3 & 49,7 \\
\hline \multicolumn{9}{|c|}{ Мясо-молочный тип (п=10) } \\
\hline Утро & 20,1 & 29,5 & 20,0 & 30,4 & 40,1 & 59,9 & 49,6 & 50,4 \\
\hline Обед & 20,3 & 29,8 & 21,3 & 28,6 & 41,6 & 58,4 & 50,1 & 49,9 \\
\hline Вечер & 19,8 & 29,7 & 20,4 & 30,1 & 40,2 & 59,8 & 49,5 & 50,5 \\
\hline За сутки & 20,1 & 29,7 & 20,5 & 29,7 & 40,6 & 59,4 & 49,8 & 50,2 \\
\hline
\end{tabular}

\% (табл. 5).

В среднем, по многочисленным литературным данным, удои правой и левой половин вымени почти равны, то есть составляют 50 \% общего удоя. Исследования показали, что в изученной популяции коров симментальской породы удои правой половины вымени в среднем составили 50,6 \% с колебаниями в отдельных внутрипородных типах от 49,8 до 51,8 \%.

Индекс соответствия передних и задних долей, по И. Иоганнсону и др. [1], в значительной степени обусловлен генотипом и породой. Согласно их данным, в среднем около 45 \% общей изменчивости соотношения передних и задних долей (внутри пород) обусловлено генетически, поэтому путем соответствующего племенного отбора и подбора можно значительно улучшить пропорции вымени.

Корреляция между молочной продуктивностью коров и объемом вымени оказалась более высокой $(r=0,376)$ у коров молочного и молочномясного ( $r=0,347)$ типов, и она меньше выражена у коров мясо-молочного типа $(r=0,264)$.

Выводы

Таким образом, морфофизиологические свойства вымени являются важнейшими селекционными признаками. В симментальской породе скота лучшими технологическими свойствами вымени характеризуются коровы молочного и молочно-мясного типов. Для определения пригодности коров к условиям высокомеханизированных ферм желательно из всех показателей морфофизиологических свойств вымени, кроме продуктивных качеств, использовать развитие четвертей вымени и интенсивность молокоотдачи.

\section{Библиографический список}

1. Боев, М.М. Селекция симментальского скота по молочной продуктивности / М.М. Боев, Э.И.Бибикова, Н.С. Колышкина . - М.: Агропромиздат, 1987. - 174 с.

2. Эрнст, Л.К. Современные методы совершенствования молочного скота / Л.К. Эрнст, В.А. Чемм . - М.: Колос, 1972.-375 с.

3. Бондарь, Р.М. Размер, форма вымени и сосков, скорость молокоотдачи как признаки отбора коров: дисс. ... канд. с.-х. наук / Р.М.Бондарь. - Белая Церковь, 1968.-137 с.

4. Дедов, М.Д. Создание заводского типа симментальского скота методом чистопородной селекции / М.Д. Дедов, М.Г. Спивак // Аграрная 
Россия.-1999.-№2(3).-С.38-45.

5. Демьянов, В.В. Совершенствование симментальского скота Поволжья / В.В. Демьянов // Степные просторы.-1968.-№10.-С.14-15.

6. Демьянов, В.В. О совершенствовании вымени симментальских коров / В.В.Демьянов // Молочное и мясное скотоводство.-1972.-№ 5.C.12-14.

7. Дедов, М.Д. Состояние и направление племенной работы с симментальской и сычевской породами скота / Методы совершенствования симментальского и сычевского скота в СССР // М.Д. Дедов, М.Г. Спивак . - М.: Колос, 1982.$186 \mathrm{c}$.

8. Катмаков, П.С. Создание новых высокопродуктивных типов и популяций молочного скота / П.С. Катмаков, Е.И. Анисимова. - Ульяновск, 2010. -242 с.

9. Хайсанов, Д.П. Использование голштинской породы в молочном скотоводстве Поволжья / Д.П. Хайсанов, П.С. Катмаков, В.П. Гаври-
ленко.-Ульяновск, 1997. - 307 с.

10. Катмаков, П.С. Совершенствование симментальской породы методами внутрипородной селекции и скрещивания / П.С. Катмаков, Е.И. Анисимова.- Ульяновск, 2017. - 188 с.

11. Велиток, И.Г. Технология машинного доения коров / И.Г.Велиток.-М.: Колос, 1975.- 256 с.

12. Иоганссон, И. Форма вымени, легкость отдачи молока и молочная продуктивность / И. Иоганссон, Я. Рендель, О. Граверт // Генетика и разведение животных.- М.: Колос, 1970.- С.191211.

13. Гарькавый, Ф.Л. Селекция коров и машинное доение / Ф.Л. Гарькавый.- М.: Колос, 1974.-160 c.

14. Всяких А.С. Импортный скот в СССР / А.С.Всяких, И.С. Куринский.- М.,1976.-288 с.

15. Меркурьева, Е.К. Биометрия в селекции и генетике сельскохозяйственных животных / Е.К.Меркурьева.- М.: Колос,1970.- 424 с.

\title{
EVALUATION OF MORPHOFUNCTIONAL UDDER PROPERTIES OF SIMMENTAL COWS OF DIFFERENT INTRABREEDING TYPES
}

\author{
Anisimova E.I., Katmakov P.S. \\ FSBEI HE Ulyanovsk SAU \\ FSBSI "Research Institute of the Southeast" \\ 432017, Ulyanovsk, Novyy Venets Boulevard, 1; tel .: 8 (8422) 44-30-62 \\ e-mail: ulbiotech@yandex.ru
}

Key words: Simmental breed, intra-breed type, constitution, morphological evaluation, functional properties, correlation, heritability, udder index, milk flow, breed plasticity.

The work is devoted to evaluation of morphofunctional udder properties of Simmental cows of different intra-breed types. It was found that $70.3 \%$ of the cows had the desired udder cuplike shape among the animals of the dairy type. This parametre is 4.3-21.5\% higher than among the representatives of dairymeat and meat-dairy types. Cows with a cup-shaped udder showed productivity in the third lactation of $5500-5700 \mathrm{~kg}$ of milk and were superior to those who had a rounded udder shape by $900 \mathrm{~kg}$ and with a goat udder by $1300 \mathrm{~kg}$. Cows of dairy type are characterized by a more massive udder, the total score is 4.5 points, the milk-and-meat cows have 4.2 and the meat-and-milk type has 4.0 points. A positive correlation was found between the milk yield and the volume of udders. It was 0.376 of milk type cows, while of cows of dairy-meat and meat-milk types it 0.347 and 0.264 accordingly. It was established that cows of milk type have greater girth dimensions, udder length and width than cows of other intrabreed types by 3,7 to 4,9;1,3-2,1, respectively; and 1,1-1,8 cm. The cows of the milk type were also characterized by the highest milk yield rate, this index was higher in comparison with milk-meat and meat-milk types, during the first lactation by 0,11-0,32 kg/min., during the second - by 0,11-0,18 kg/min and during the third - by 0,29-0,42 kg/min. Dairy cows are more technological, their udder index was $44.7 \%$, closer parametres had cows of milk - meat type with an index of $43.2 \%$ and the least technological are cows of meat - milk type with an udder index of $40.6 \%$. Of the total daily milk yield of dairy cows, $44.7 \%$ of milk is from the front quarters of the udder, $55.3 \%$ - from the rear quarter, $51.8 \%$ - from the right half, and $48.2 \%$ - from the left half.

Bibliography

1. Boev, M.M. Selection of Simmental cattle for milk productivity / M.M. Boev, E. I. Bibikova, N.S. Kolyshkin.-M .: Agropromizdat, 1987.-174 p.

2. Ernst, L.K. Modern methods of improving dairy cattle / L.K. Ernst, V.A. Chemm. -M .: Kolos, 1972.-375 p.

3. Bondar, R.M. The size, shape of udder and dugs, the rate of milk flow as signs of selection of cows: dissertation of Candidate of Agriculture / R.M. Bondar.-Belaya Tserkov, 1968.-137p.

4. Dedov, M.D. Creation of Simmental cattle of farm type by the metans of purebred selection / M.D. Dedov, M.G. Spivak // Agrarian Russia.-1999.-№2 (3) - - P.38-45.

5. Demyanov, V.V. Improvement of Simmental cattle of the Volga region / V.V. Demyanov // Steppe open spaces.-1968.- №10.-P.14-15.

6. Demyanov, V.V. On the issue of udder improvement of Simmental cows / V.V. Demyanov // Dairy and meat cattle breeding.-1972.-№ 5.-P.12-14.

7. Dedov, M.D. State and direction of breeding work with Simmental and Sychevskaya cattle breeds / Methods of improving Simmental and Sychevsky cattle in the USSR //M.D. Dedov, M.G. Spivak. - M.: Kolos, 1982. - 186 c.

8. Katmakov, P.S. Creation of new highly productive types and populations of dairy cattle / P.S. Katmakov, E.I. Anisimova. - Ulyanovsk, $2010 .-242$ p. $307 p$.

9. Khaysanov, D.P. Usage of Holstein breed in dairy cattle breeding in the Volga region / D.P. Khaysanov, P.S. Katmakov, V.P. Gavrilenko.-Ulyanovsk, 1997.-

10. Katmakov, P.S. Improvement of Simmental breed by means of intra-breed breeding and crossing / P.S. Katmakov, E.I. Anisimova .- Ulyanovsk, 2017.$188 \mathrm{p.}$.

11. Velitok, I.G. The technology of machine milking of cows / I.G. Velitok.-M .: Kolos, 1975.- 256 p.

12. logansson, I. The shape of udder, the ease of milk giving and milk productivity/I. logansson, Ya. Rendel, O. Gravert // Genetics and animal breeding. Moscow: Kolos, 1970.-P.191-211.

13. Garkavy, F.L. Selection of cows and machine milking / F.L. Garkavy .- Moscow: Kolos, 1974.-160 p.

14. Vsyakikh A.S. Imported cattle in the USSR / A.S. Vsyakikh, I.S. Kurinsky.- M., 1976.-288 p.

15. Merkuryeva, E.K. Biometrics in selection and genetics of farm animals / E.K. Merkuryeva -- Moscow: Kolos, 1970.- $424 p$. 